\title{
Are stock prices too volatile to be justified by the dividend discount model?
}

\author{
Levent Akdeniz*, Aslıhan Altay Salih, Süleyman Tuluğ Ok \\ Faculty of Business Administration, Bilkent University, 06800 Bilkent, Ankara, Turkey
}

Received 22 June 2006; received in revised form 11 October 2006

Available online 27 November 2006

\begin{abstract}
This study investigates excess stock price volatility using the variance bound framework of LeRoy and Porter [The present-value relation: tests based on implied variance bounds, Econometrica 49 (1981) 555-574] and of Shiller [Do stock prices move too much to be justified by subsequent changes in dividends? Am. Econ. Rev. 71 (1981) 421-436.]. The conditional variance bound relationship is examined using cross-sectional data simulated from the general equilibrium asset pricing model of Brock [Asset prices in a production economy, in: J.J. McCall (Ed.), The Economics of Information and Uncertainty, University of Chicago Press, Chicago (for N.B.E.R.), 1982]. Results show that the conditional variance bounds hold, hence, our hypothesis of the validity of the dividend discount model cannot be rejected. Moreover, in our setting, markets are efficient and stock prices are neither affected by herd psychology nor by the outcome of noise trading by naive investors; thus, we are able to control for market efficiency. Consequently, we show that one cannot infer any conclusions about market efficiency from the unconditional variance bounds tests.
\end{abstract}

(C) 2006 Elsevier B.V. All rights reserved.

Keywords: Asset pricing; Variance bounds; Dividend discount model; Market efficiency; Excess volatility

\section{Introduction}

Tests of market efficiency have attracted the attention of many scholars of financial economics. Most of the literature concentrates on the price formation process: the speed and quality of the information and its effect on prices. Shiller [1] takes a different perspective by using the variance bounds framework; he develops a test of market efficiency from a simple valuation model, which claims that prices are the present value of a rational expectation of future dividends. He concludes that stock prices are "too volatile" to be in line with efficient markets and that the valuation model cannot, by itself, explain the movement in stock prices.

However, Kleidon [2] strongly opposes Shiller's methodology; he employs Monte-Carlo simulation of a statistical model to show that the valuation model holds and is consistent with market efficiency. More specifically, Kleidon argues that Shiller's use of ex-post dividends to test the valuation model is incorrect, since this data is not available when prices are set, i.e., the model cannot be constructed assuming that investors

*Corresponding author. Tel./fax: + 903122902202.

E-mail addresses: akdeniz@bilkent.edu.tr (L. Akdeniz), asalih@bilkent.edu.tr (A.A. Salih), tulug@bilkent.edu.tr (S.T. Ok). 
know the future dividend stream at the time of the stock price valuation. Demand for a stock depends on its expected future dividends, and these dividends depend on different possible states of the economy. Thus, an ex-post dividend series is only one of many possible realizations. Kleidon uses Monte-Carlo simulation to demonstrate that the variance bound relation is a cross-sectional matter; thus, it should be tested using different realizations of dividends caused by different states of the economy.

Shiller [1] detrends the price and corresponding perfect forecast price series by dividing these series by a long-term growth factor in order to attain stationarity. On the other hand Kleidon [2] simulated a random walk (i.e., a nonstationary process) series and used a difference stationary testing framework to critique Shiller [1] by demonstrating that variance bounds are not violated in his setup. Nelson and Plosser [3] argues that false rejections can easily occur when the data are actually difference stationary but the investigator sets up the testing framework in a trend stationary model. We derive our findings from a stationary economic model thus unit root arguments play no role in our results.

Since the first variance bounds papers by LeRoy and Porter [4] and Shiller [1], there has been a vast literature $^{1}$ on the excess volatility of stock prices. West [5] provides an excellent review of the original studies on stock price volatility. In his review, he concludes that there is excess volatility in the stock market. Although possible explanations were offered for excess volatility: small-sample bias [9-11,16], rational bubbles $[12-14,17]$, and fads created by naive investors $[18,19]$, none of these led to a valuation model that explains the data better than the traditional present-value model. Campbell and Shiller $[20,21]$ take excess volatility in stock prices as a given and relate this excess volatility to the predictability of returns. Recently, Rodriguez et al. [22] linked asset returns to fundamental macro economic variables and argued that these variables explained the excess volatility in asset prices. In addition, Bansal and Lundblad [23] econometrically model the cash flow growth rates and the time variation in the cost of capital to estimate the asset prices. Using these estimated prices, they conclude that the present-value model captures observed volatility in equity prices.

Asset price volatility has attracted a lot of attention in the area of Finance. Researchers have explored different venues to find explanations for asset price volatility. One line of attack has been that of Bansal and Yaron [24], Bekaert et al. [25], Lettau et al. [26] who form the link between asset price volatility and macroeconomic volatility. Another line has been that of Pritsker [27] who demonstrates the relationship between asset price volatility and changes in financial markets. More specifically, Pritsker [27] argues that if large investors are forced to sell due to some reasons, they can temporarily cause assets to be mispriced, thus asset prices no longer reflect the behavior of long run fundamentals.

In this study, we argue that the pronounced excess volatility of asset prices documented through variance bound test literature is misleading. We employ a production based asset-pricing model and show that the variance bound tests are neither test of market efficiency nor of the present-value model. Specifically, we use Brock's [28] general equilibrium model of asset pricing to investigate the excess stock price volatility and its implications for market efficiency. Our results are derived from a theoretical economic model rather than a statistical number-generating procedure or an econometrically derived price series. Therefore, in our setting, (1) the economy, by construction is efficient and it produces the maximally possible amount of welfare for society, and (2) asset prices reflect the utility-maximizing behavior of consumers and the profit-maximizing behavior of firms.

The variance bound tests presented in Shiller [1] and in LeRoy and Porter [4] actually test joint hypotheses of market efficiency and the validity of the simple valuation model of Miller and Modigliani [29]; therefore the violation of the variance bound, by itself, cannot be adequate evidence against market efficiency. However, in our setting, markets are efficient by construction, and stock prices are affected neither by herd psychology nor by the outcome of noise trading by naive investors.

The organization of the paper is as follows. In Section 2, we provide a brief summary of the original variance bounds tests. Section 3 introduces the model. Section 4 describes the solution and provides the parameters of the model. Section 5 discusses the methodology. Section 6 presents results, and Section 7 concludes the paper.

\footnotetext{
${ }^{1}$ Michener [6], Stock [7], LeRoy [8], Flavin [9], Kleidon [2], Mankiw et al. [10], Marsh and Merton [11], DeBondt and Thaler [12], West [13], Tirole [14], Gurkaynak [15].
} 


\section{Background}

The simple valuation model of Miller and Modigliani [29] characterizes the stock price as the present value of rationally expected future dividends, i.e.,

$$
p_{t}=\sum_{\tau=1}^{\infty} \frac{E\left(\tilde{d}_{t+\tau} \mid \Phi_{t}\right)}{(1+r)^{\tau}}
$$

where $r$ is the discount rate and $d_{t}$ is dividends at time $t$, where the investors base their expectations conditional on $\Phi_{t}$, the information set at time $t$. Shiller [1] defines the perfect foresight price (the ex-post price with perfect information about future dividends) as

$$
p_{t}^{*} \equiv \sum_{\tau=1}^{\infty} \frac{d_{t+\tau}}{(1+r)^{\tau}},
$$

where $d_{t}$ is the realized dividend. If investors are rational, their dividend expectation should be equal to the realized dividend:

$$
p_{t}=E\left\{p_{t}^{*} \mid \Phi_{t}\right\}
$$

The expectation is conditional on $\Phi_{t}$, the information investors have at date $t$ :

$$
p_{t}=p_{t}^{*}+u_{t}
$$

Since $p_{t}$ equals $p_{t}^{*}$ plus an error term, which is orthogonal to $p_{t}^{*}$ under rational expectations, we must have

$$
\operatorname{var}\left(p_{t}^{*}\right) \geqslant \operatorname{var}\left(p_{t}\right)
$$

Note that the actual price $p_{t}$, at time $\mathrm{t}$ depends on the realization from distribution of the error term at time $t$. Therefore, the variance bound given in Eq. (2.3) has to hold cross-sectionally, as the information available at time $t-1$ determines the possible values of the present value of dividends. Thus, the variance bounds relationship should hold in terms of conditional variances, i.e.,

$$
\operatorname{var}\left(p_{t}^{*} \mid \Phi_{t-k}\right) \geqslant \operatorname{var}\left(p_{t} \mid \Phi_{t-k}\right),
$$

where $\Phi$ is the conditioning information available to investors at time $t-k$.

Shiller [1] and Leroy and Porter [4] use time-series data to test the above variance bound relationship on unconditional variances, assuming stationarity and ergodicity of price series and document that the variance bound relationship is violated. However, data points in a time series data set correspond to only one realization of many possible economies at any point in time. More specifically, a stock's price depends on its expected future dividends, yet expectations of future dividends are formed over different possible states of the economy. Thus, an ex-post dividend series is only one of many possible realizations. ${ }^{2}$ Moreover, the violation of the variance bound infers the rejection of both market efficiency and the valuation model due to the joint hypothesis problem.

In this study, we test the conditional variance bound relationship in Eq. (2.4) using cross-sectional data, which is generated from the simulation of Brock's [28] general equilibrium economic growth model. Simulation is an invaluable tool that enhances researchers' ability to analyze dynamic economic models. A researcher can explore empirical debates by employing those models in a laboratory environment and incorporating all possible states of an economy. Over the last two decades, more and more economists have been using simulation methods for analyzing empirical problems. As Judd [30] points out, the computational methods provide a strong complement to economic theory for problems that are not analytically tractable.

\footnotetext{
${ }^{2}$ See Kleidon [2] for a detailed discussion.
} 


\section{Model}

\subsection{The growth model}

The model we use as the basis for our study is the standard growth model with production, as specified in Brock [28] and in Brock [31]. In his papers, Brock shows how the stochastic economic growth model can be used to solve for asset prices in a production based economy. This is a model of economic growth with an infinitely lived representative consumer. In this section, we borrow heavily from Brock and recapitulate the essential elements of the model.

The working of the model, according to Brock [31], is almost self-explanatory: There are $N$ different processes in this economy. At date $t$, it is decided how much to consume and how much to hold in the form of capital. It is assumed that capital goods can be costlessly transformed into consumption goods on a one-forone basis. After the allocation is decided, nature reveals the value of shock and each process produces a different level of output at the end of period $t$. However, due to the depreciation, some level of capital evaporates at the end of period $t$. Thus net output available to be divided into consumption and capital stock at date $t+1$ is the sum of all processes' output plus capital minus the depreciation. This net output is divided into consumption and capital stock at the beginning of date $t+1$, and so on it goes.

The formal representation of the problem is as follows. The representative agent's objective is to maximize the expected value of the discounted sum of utilities over all consumption paths and capital allocations: ${ }^{3}$

$$
\begin{aligned}
& \max _{c_{t}, x_{i t}} E\left[\sum_{t=0}^{\infty} \beta^{t} u\left(c_{t}\right)\right], \\
& \text { subject to : } x_{t}=\sum_{i=1}^{N} x_{i t}, \\
& y_{t+1}=\sum f\left(x_{i t}, \xi\right), \\
& c_{t}+x_{t}=y_{t}, \\
& c_{t} x_{i t} \geqslant 0, \\
& y_{0} \text { historically given, }
\end{aligned}
$$

where $E$ is the mathematical expectation operator, $\beta$ the discount factor on future utility, $u$ the utility function of consumption, $c_{t}$ the consumption at date $t, x_{t}$ the capital stock at date $t, y_{t}$ the output at date $t, f_{i}$ the production function of process $i$ plus un-depreciated capital, $x_{i t}$ the capital allocated to process $i$ at date $t, \delta_{i}$ is the depreciation rate for capital installed in process $i$, and $\xi_{t}$ is the shock parameter.

Note that $f_{i}\left(x_{i t}, \xi_{t}\right)=g_{i}\left(x_{i t}, \xi_{t}\right)+\left(1-\delta_{i}\right) x_{i t}$, where $g_{i}\left(x_{i t}, \xi_{t}\right)$ is the production function of process $i$.

The main assumptions of this model are:

(A1) the functions $u$ and $f_{i}$ are concave, increasing, twice continuously differentiable, and satisfy the Inada conditions;

(A2) the stochastic process is independent and identically distributed;

(A3) the maximization problem has a unique optimal solution.

The first-order conditions for the intertemporal maximization are:

$$
u^{\prime}\left(c_{t-1}\right)=\beta \mathrm{E}_{t-1}\left[u^{\prime}\left(c_{t}\right) f_{i}^{\prime}\left(x_{i t}, \xi_{t}\right)\right],
$$

\footnotetext{
${ }^{3}$ The $x$ 's at date $t$ must be measurable with respect to the $x_{i}$ 's through date $t-1$.
} 
and the transversality condition is

$$
\lim _{t \rightarrow \infty} \beta^{t} \mathrm{E}_{t-1}\left[u^{\prime}\left(c_{t}\right) x_{i t}\right]=0 .
$$

Eq. (3.7) is used to derive a numerical solution to the growth model. Since the problem given by Eq. (3.1)-(3.6) is time stationary, the optimal levels of $c_{t}, x_{t}$, and $x_{i t}$ are functions of the output level $y_{t}$, and can be written as:

$$
c_{t}=g\left(y_{t}\right), \quad x_{t}=h\left(y_{t}\right), \quad x_{i t}=h_{i}\left(y_{t}\right) .
$$

The objective is to solve the growth model for the optimal investment functions, $h_{i}$, in order to analyze the underlying implications of the asset-pricing model. The first two functions in Eq. (3.9) can be expressed in terms of these investment functions:

$$
\begin{aligned}
& h(y)=\sum_{i=1}^{N} h_{i}(y), \\
& c(y)=y-h(y) .
\end{aligned}
$$

Given these functions, one can then define the next period's output given the current level of output, $y$, and the shock, $\xi$ :

$$
Y(y, \xi)=\sum_{i=1}^{N} f_{i}\left(h_{i}(y), \xi\right) .
$$

A numerical solution to this problem consists of policy functions (3.9) that satisfy

$$
\left.\left.u^{\prime}(c(y))=\beta E\left[u^{\prime}(c) Y(y, \xi)\right)\right) f_{i}^{\prime}\left(h_{i}(Y(y, \xi)), \xi\right)\right],
$$

for all $y$ and for which the transversality condition (3.8) holds. Further details are in Akdeniz and Dechert [32].

\subsection{An asset pricing model}

The asset-pricing model in Brock [31] is much like the Lucas [33] model. The main difference is that Brock's model includes production; by incorporating shocks in the production processes, it directly ties the sources of uncertainty in asset prices to economic fluctuations in output levels and, hence, to profits.

Brock's model is similar to the growth model. There is one representative consumer whose preferences are given in Eq. (3.1). On the production side, there are $\mathrm{N}$ different firms. Firms rent capital from the consumer side at rate $r_{i t}$ to maximize their profits:

$$
\pi_{i, t+1}=f_{i}\left(x_{i t}, \xi_{t}\right)-r_{i t} x_{i t} .
$$

Each firm makes its decision to hire capital after the shock, $\xi_{t}$, is revealed. Here, $r_{i t}$ denotes the interest rate on capital in industry $i$ at date $t$ and is determined within the model. Asset shares are normalized so that there is one perfectly divisible equity share for each firm. Ownership of a share in firm $i$ at date $t$ entitles the consumer to the firm's profits at date $t+1$. It is also assumed (as in Lucas [33]) that the optimum levels of asset prices, capital, consumption and output form a rational expectations equilibrium.

The representative consumer takes asset prices, profits and rents as given and solves the following problem:

$$
\begin{aligned}
& \max \mathrm{E}\left[\sum_{t=0}^{\infty} \beta^{t} u\left(c_{t}\right)\right], \\
& \text { subject to } c_{t}+x_{t}+P_{t} Z_{t} \leqslant \pi_{t} Z_{t-1}+P_{t} Z_{t-1}+\sum_{i=1}^{N} r_{i, t-1} x_{i, t-1}, \\
& c_{t}, Z_{t}, x_{i t} \geqslant 0, \\
& r_{i t}=f_{i}^{\prime}\left(x_{i t}, \xi_{t}\right),
\end{aligned}
$$




$$
\pi_{i t}=f_{i}\left(x_{i, t-1}, \xi_{t-1}\right)-f_{i}^{\prime}\left(x_{i, t-1}, \xi_{t-1}\right) x_{i, t-1},
$$

where $P_{i t}$ is the price of one share of firm $i$ at date $t, Z_{i t}$ the number of shares of firm $i$ owned by the consumer at date $t$, and $\pi_{i t}$ are the profits of firm $i$ at date $t$. The details of the model are in Brock [31]. The first-order conditions yielded by the maximization problem are:

$$
P_{i t} u^{\prime}\left(c_{t}\right)=\beta E_{t}\left[u^{\prime}\left(c_{t+1}\right)\left(\pi_{i, t+1}+P_{i, t+1}\right)\right]
$$

and

$$
u^{\prime}\left(c_{t}\right)=\beta E_{t}\left[u^{\prime}\left(c_{t+1}\right) f_{i}^{\prime}\left(x_{i, t+1}, \xi_{t+1}\right)\right]
$$

from which we get the prices for the assets. In addition, the transversality conditions

$$
\begin{aligned}
& \lim _{t \rightarrow \infty} \beta^{t} E_{0}\left[u^{\prime}\left(c_{t}\right) \sum_{i} P_{i t} Z_{i t}\right]=0, \\
& \lim _{t \rightarrow \infty} \beta^{t} E_{0}\left[u^{\prime}\left(c_{t}\right) x_{t}\right]=0,
\end{aligned}
$$

are needed to fully characterize the optimum. Brock [28] shows that there is a duality between the growth model (3.1)-(3.6) and the asset-pricing model (3.10)-(3.14); the solution to the growth model is also the solution to the asset-pricing model. Once the solution to the growth model is obtained, the asset pricing functions can be solved for the prices of the assets by Eq. (3.15). As for the transversality condition, Judd [34] points out that it implies that we are looking for a bounded solution to the growth model.

Since (in equilibrium) there is 1 share of each asset, the equally weighted market portfolio is

$$
M_{t}=\sum_{i=1}^{n} P_{i t},
$$

and the dividends (profits) are

$$
\pi_{t}=\sum_{i=1}^{n} \pi_{i t} .
$$

Now we define the profit, consumption and output functions by

$$
\begin{aligned}
& \pi_{i}(y, \xi)=f_{i}\left(h_{i}(y), \xi\right)-h_{i}(y) f_{i}^{\prime}\left(h_{i}(y), \xi\right), \\
& c(y)=y-\sum_{i=1}^{N} h_{i}(y), \\
& Y(y, \xi)=\sum_{i=1}^{N} f_{i}\left(h_{i}(y), \xi\right),
\end{aligned}
$$

and the asset pricing functions by

$$
P_{i}(y) u^{\prime}(c(y))=\beta \mathrm{E}\left[u^{\prime}(c(Y(y, \xi)))\left(P_{i}(Y(y, \xi))+\pi_{i}(y, \xi)\right)\right] .
$$

Once we have the solution of the growth model, we are able to calculate both dividends and asset prices at different output and shock levels.

\section{The solution of the model}

Except for a special case of the utility and production functions, there are no closed form solutions of the optimal investment functions for the problem outlined in Eq. (3.1)-(3.6). ${ }^{4}$ One must use numerical techniques in order to analyze the properties of the solutions to the asset-pricing model. Akdeniz and Dechert [32] report the technical details of the numerical solution; we will not repeat them here. In this study, we use that solution

\footnotetext{
${ }^{4}$ The special case is for a $\operatorname{logarithmic}$ utility function, $u(c)=\log (c)$, and for Cobb-Douglas firms, $f_{i}\left(x, \xi_{i}\right)=\xi_{i} x^{\alpha}$, where the value of $\alpha$ is common to all firms. In this case, the optimal investment policy functions are linear in output.
} 
Table 1

Production function parameters

\begin{tabular}{|c|c|c|c|}
\hline State & $\alpha$ & $\theta$ & $\delta$ \\
\hline \multicolumn{4}{|c|}{ Firm 1} \\
\hline 1 & 0.50 & 0.36 & 0.15 \\
\hline 2 & 0.42 & 0.50 & 0.15 \\
\hline 3 & 0.48 & 0.49 & 0.15 \\
\hline 4 & 0.45 & 0.40 & 0.15 \\
\hline 5 & 0.44 & 0.48 & 0.15 \\
\hline 6 & 0.49 & 0.49 & 0.15 \\
\hline 7 & 0.54 & 0.34 & 0.15 \\
\hline 8 & 0.38 & 0.54 & 0.15 \\
\hline \multicolumn{4}{|c|}{ Firm 2} \\
\hline 1 & 0.40 & 0.29 & 0.10 \\
\hline 2 & 0.51 & 0.27 & 0.10 \\
\hline 3 & 0.44 & 0.28 & 0.10 \\
\hline 4 & 0.49 & 0.24 & 0.10 \\
\hline 5 & 0.45 & 0.31 & 0.10 \\
\hline 6 & 0.35 & 0.44 & 0.10 \\
\hline 7 & 0.45 & 0.26 & 0.10 \\
\hline 8 & 0.50 & 0.28 & 0.10 \\
\hline \multicolumn{4}{|c|}{ Firm 3} \\
\hline 1 & 0.52 & 0.47 & 0.20 \\
\hline 2 & 0.41 & 0.68 & 0.20 \\
\hline 3 & 0.37 & 0.85 & 0.20 \\
\hline 4 & 0.49 & 0.50 & 0.20 \\
\hline 5 & 0.35 & 0.77 & 0.20 \\
\hline 6 & 0.55 & 0.56 & 0.20 \\
\hline 7 & 0.45 & 0.53 & 0.20 \\
\hline 8 & 0.52 & 0.54 & 0.20 \\
\hline
\end{tabular}

and explore the parameter space for solutions that, to a certain extent, fit some of the stylized facts of asset markets. In this section we present the functional forms and the parameter values that we used in the solution of the growth model. We use a constant relative risk aversion (CRRA) utility function,

$$
u(c)=\frac{c^{1-\gamma}}{1-\gamma},
$$

where $\gamma$ is the utility curvature parameter. Campbell and Cochrane [35] estimate that a CRRA utility function with a utility curvature parameter of 2 matches the postwar US data, so we use $\gamma=2$ for the value of the utility curvature parameter. In keeping with the common practice in the literature, we choose a value for the utility discount parameter, $\beta$, in the range of $0.95-0.99$ in yearly units. Note that a utility discount parameter value of 0.97 approximately corresponds to a real interest rate of $3 \%$ in yearly terms. On the production side, firms are characterized by the Cobb-Douglas production functions:

$$
f(x, \xi)=\theta(\xi) x^{\alpha(\xi)}+(1-\delta(\xi)) x,
$$

where $\xi$ is the shock parameter, and $\delta$ the depreciation rate in the production function. We choose the values of $\alpha$ and $\theta$ at random. ${ }^{5}$ We solve the model for three firms and eight states of the economy. The parameters of the production function are reported in Table 1.

\footnotetext{
${ }^{5}$ Since these variables are based on the micro characteristics of various sectors of an economy, we would need empirical studies on firms to calibrate them to the US economy. It would also require knowledge of how shocks affect firms, both individually and cross-sectionally.
} 


\section{Methodology}

Once we solve the model for a given set of parameters, we are able to simulate it with the same parameter set over the state space. Through simulation, we are able to generate different time series paths of data that correspond to different state realizations. More specifically, we solve the model for three firms and eight states of the economy using the functional forms and parameter values outlined above. After obtaining the optimal policy functions, we simulated the model 1000 times over a period of 100 years in each run. In each simulation, the computer starts from the same state; hence, the model yields the same market price in year 1 and then picks a state randomly for each of the next 100 years. In the end, we obtain 1000 different sample paths of market price data for 100 years; each path has the same state and, hence, the same price level in the first year. We then derive the perfect-foresight price, $p_{t}^{*}$ for each series according to the following recursion:

$$
p_{t}^{*}=\frac{p_{t+1}^{*}+d_{t+1}}{1+r}
$$

subject to a condition that equates the terminal $p_{t}^{*}$ to the terminal $p_{t}$. We calculate the perfect foresight price at five different discount rates, $1 \%, 2 \%, 3 \%, 4 \%$ and $5 \%$. In the end, we have 1000 sets of realized market price, $p_{t}$ and perfect-foresight price, $p_{t}^{*}$ series, each starting off at the same price level. With these 1000 sets of time series paths of simulated data, we have the luxury of conducting cross-sectional analysis.

\section{Results}

In Fig. 1, for economies 10, 20, and 50, we plot the time series market price and the corresponding perfectforesight price calculated using (2.1), with $r=0.03$. Note that we call each of our 1000 series an economy, because each series has different state realizations. As can be seen in Fig. 1, our model yields realized and perfect-foresight price series similar in pattern to those of Shiller [1]. The realized price series is more volatile than the perfect-foresight price series, suggesting that the variance bound relationship in (2.3) is violated. We also calculate the standard deviation of each series $\left(p_{t}\right.$ and $\left.p_{t}^{*}\right)$ for 100 yearly observations and for 1000 replications using different discount factors, namely $1 \%, 2 \%, 3 \%, 4 \%$ and $5 \%$ to observe the sensitivity of the bound with respect to discount factor.

In Table 2, we report some statistics on the distribution of $s\left(p_{t}\right) / s\left(p_{t}^{*}\right)$ where " $s$ " refers to sample standard deviation. As can be seen in Table 2, in 986 of the 1000 time series sample paths, the standard deviation of the actual price series is greater than the standard deviation of the perfect foresight price series when the perfectforesight price series is discounted by $3 \%$. F-tests also confirm that the variance of the actual price series is significantly greater than the variance of the perfect foresight price series in 953 replications; this result is significant at the $1 \%$ level. The volatility of the actual price series is higher than the perfect-foresight price series in a majority of cases for all discount rates, indicating a violation of the unconditional variance bound relationship of Eq. (2.3).

Shiller [1] reports similar findings using S\&P 500 price data and concludes that violation of the variance bound is enough evidence against the valuation model and market efficiency. We replicate his procedure in an efficient market setting and show that the variance bound relationship is still violated. Asset prices in Brock's general equilibrium model reflect the utility-maximizing behavior of rational consumers and the profitmaximizing behavior of producers. Hence, it is an efficient market by design. More specifically, the model we use in this study does not incorporate behavioral aspects of investors into asset prices; therefore neither fads created by naive investors, nor bubbles are reflected in prices. Thus, we show that the violation of the unconditional variance bound relationship does not necessarily indicate market inefficiency.

Next, we examine the conditional variance bound relationship in Eq. (2.4) using cross-sectional data in order to test the valuation model in Eq. (2.1). As explained before, we start the program from the same state and, hence, the same price level, and then we produce 1000 series of prices for 100 yearly observations. We use the $1 \%, 2 \%, 3 \%, 4 \%$ and $5 \%$ as discount rates for the perfect foresight price series. Note that each of the 1000 iterations starts at the same economic state, and the states in the remaining 99 time periods are assigned randomly. In the end, we have 1000 series of 100 yearly observations. Then, we are able to calculate the standard deviation of both the actual and perfect-foresight price in year 2 across 1000 different economies. 


\section{Economy 10}

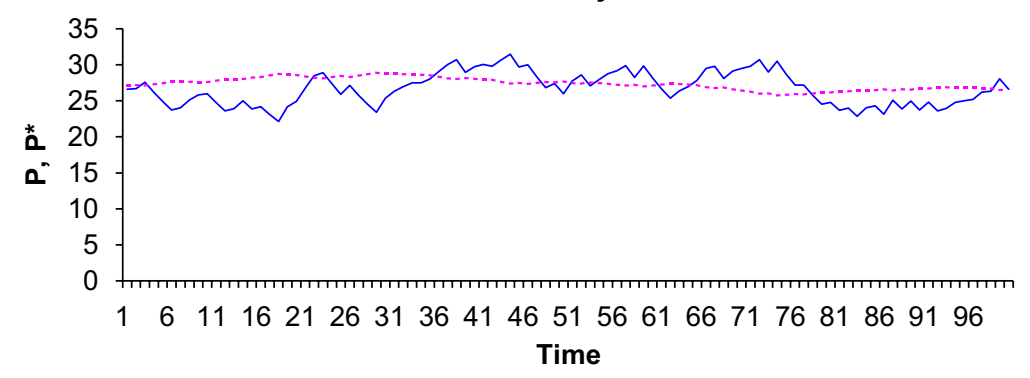

Economy 20

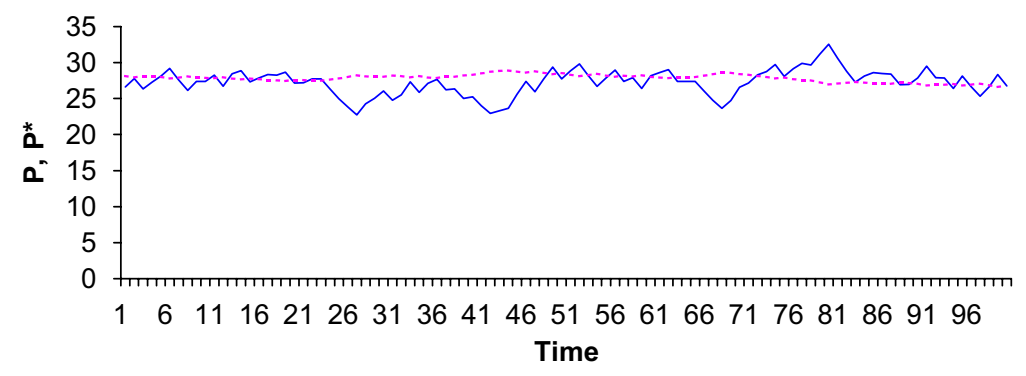

Economy 50

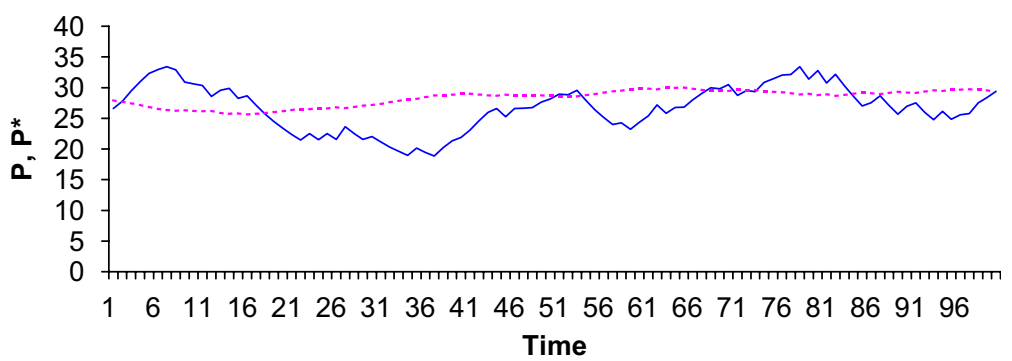

Fig. 1. Time series plots of price $p_{t}$, (solid line) and corresponding perfect-foresight price $p_{t}^{*}$, (dotted line) series over 100 time periods for economies 10, 20 and 50, with a constant discount rate $r=0.03$.

Table 2

Descriptive statistics of the distribution of ratio of standard deviation of price $p_{\mathrm{t}}$ to standard deviation of perfect-foresight price $p_{t}^{*}$ discounted at a constant discount rate, over 100 time periods for 1000 replications

\begin{tabular}{llllllll}
\hline $\begin{array}{l}\text { Utility discount } \\
\text { factor }(\beta)\end{array}$ & $\begin{array}{l}\text { Discount } \\
\text { factor }(r)\end{array}$ & $\begin{array}{l}\text { Number of } \\
\text { violations } \\
\text { (ratio }>1)\end{array}$ & $\begin{array}{l}\text { Ratio } \\
\text { mean }\end{array}$ & $\begin{array}{l}\text { Ratio standard } \\
\text { deviation }\end{array}$ & $\begin{array}{l}\text { Minimum } \\
\text { ratio }\end{array}$ & $\begin{array}{l}\text { Maximum } \\
\text { ratio }\end{array}$ & $\begin{array}{l}\text { Number of } \\
\text { significant } F \\
\text { statistics at } 1 \%\end{array}$ \\
\hline 0.99 & 0.01 & 1000 & 6.29 & 3.50 & 1.61 & 20.38 & 1000 \\
0.98 & 0.02 & 1000 & 3.70 & 1.75 & 1.07 & 10.58 & 990 \\
0.97 & 0.03 & 986 & 2.81 & 1.14 & 0.91 & 5.43 & 953 \\
0.96 & 0.04 & 984 & 2.36 & 0.83 & 0.81 & 4.39 & 885 \\
0.95 & 0.05 & 980 & 2.08 & 0.65 & & & \\
\hline
\end{tabular}

In Fig. 2, we plot the actual price and perfect-foresight price in year 2 for the first 250 economies. ${ }^{6}$ As can be seen in Fig. 2, the perfect-foresight price series depicts a more volatile pattern than the actual price series, as the theory suggests. To see this finding more precisely, in Table 3, we report some statistics on the distribution

\footnotetext{
${ }^{6} \mathrm{We}$ choose to graph the figures of the first 250 economies for clarity. Results depicted in Fig. 2 are robust to any combination of economies.
} 

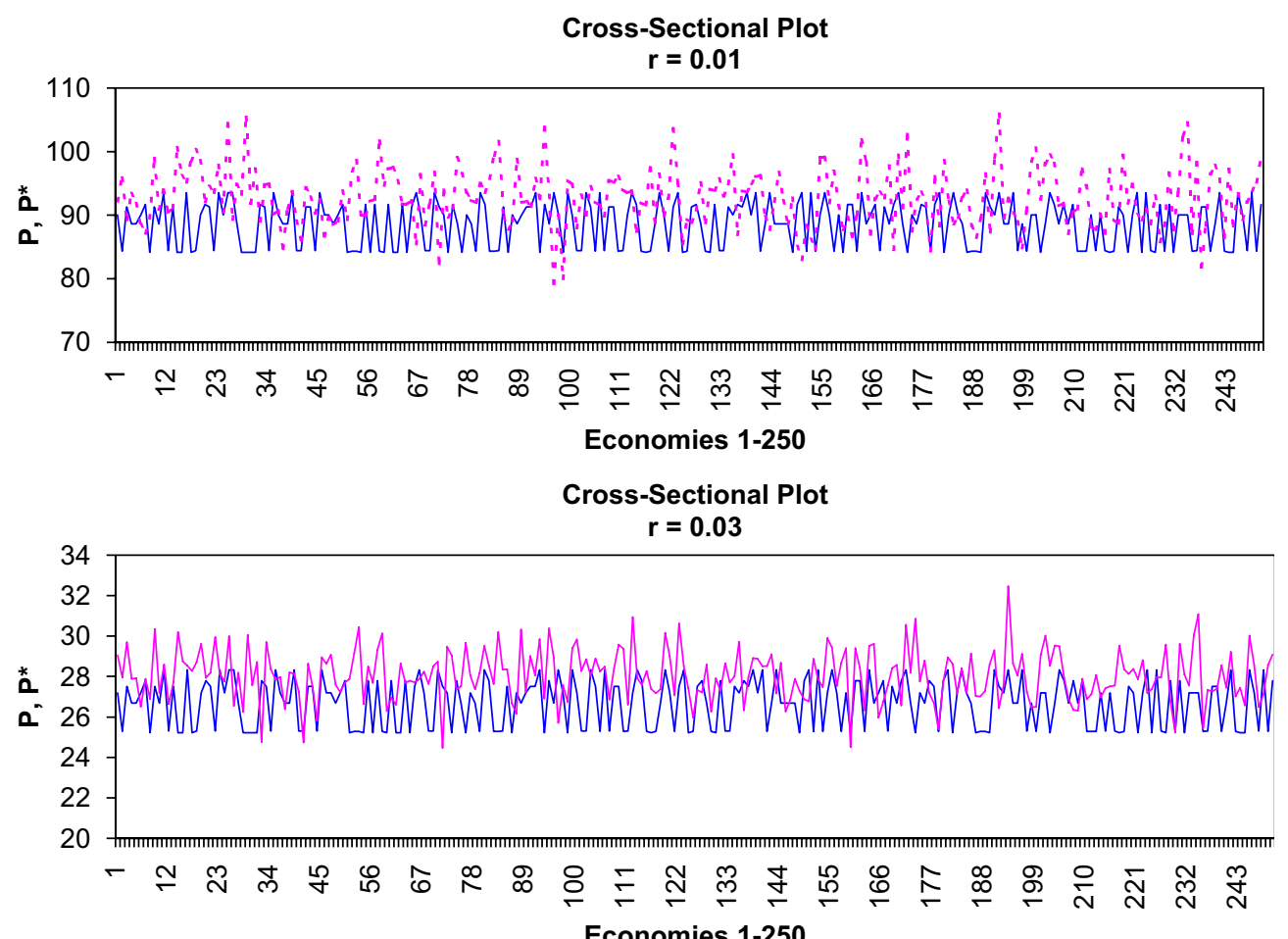

Economies 1-250

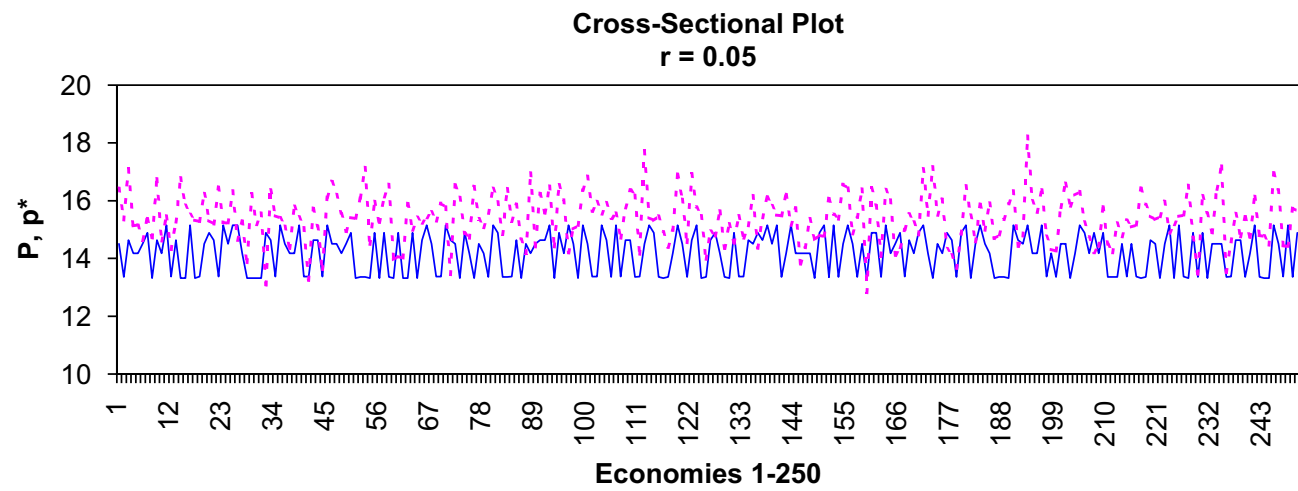

Fig. 2. Cross-sectional plot of perfect-foresight price $p_{t}^{*}$ (dotted line) and price $p_{t}$ (solid line) at time 2 across first 250 economies out of 1000 replications that are identical at time 1 , with constant discount rates $1 \%, 3 \%$ and $5 \%$.

Table 3

Descriptive statistics of the distribution of actual price, $P_{t}$, and perfect-foresight price, $p_{t}^{*}$ cross-sectionally over year $2 \mathrm{~s}$ for 1000 replications

\begin{tabular}{|c|c|c|c|c|}
\hline Utility discount factor $(\beta)$ & Discount factor $(r)$ & $s\left(P_{t}\right)$ & $s\left(P_{t}^{*}\right)$ & $F$ statistics \\
\hline 0.99 & 0.01 & 3.52 & 4.58 & $9.52 \mathrm{e}-17$ \\
\hline 0.98 & 0.02 & 1.65 & 1.78 & $8.30 \mathrm{e}-02$ \\
\hline 0.97 & 0.03 & 1.17 & 1.22 & $7.71 \mathrm{e}-02$ \\
\hline 0.96 & 0.04 & 0.87 & 0.98 & $8.46 \mathrm{e}-05$ \\
\hline 0.95 & 0.05 & 0.69 & 0.83 & $3.18 \mathrm{e}-09$ \\
\hline
\end{tabular}


of market price and the corresponding perfect-foresight price in year 2 across 1000 different economies. The results in Table 3 confirm our visual finding in Fig. 2 that perfect-foresight price series portray a more volatile pattern than the actual price series. The findings here are the opposite of what we get with time series data, suggesting that the valuation model is valid when the variance bound relationship is tested conditionally. More specifically, the variance bound relationship is a conditional variance relationship and should be tested cross-sectionally. However, since there is no way of obtaining cross-sectional real data, researchers have to rely on simulation techniques. These findings give a pause for thought that if Shiller had considered the conditional nature of the relationship in Eq. (2.1), the subsequent literature on the asset price volatility might have been less prolific and less contentious.

\section{Conclusion}

In this study, we use Brock's [28] general equilibrium model of asset pricing to investigate the pronounced excess stock price volatility and its implications for market efficiency, in line with Kleidon [2]. Shiller [1] uses time series data to test the market efficiency and validity of the present-value model of Miller and Modigliani [29] and concludes that markets are inefficient, and the valuation model is invalid. We demonstrate that this result is misleading, because the variance bound relationship is essentially a cross-sectional restriction and should only be tested using cross-sectional data.

We test the conditional variance bound with the data generated from an economic model that considers different states of the economy, thus providing a cross-sectional probability distribution of prices. In our setting, markets are efficient and stock prices are affected neither by herd psychology nor by the outcome of noise trading by naive investors; thus, the validity of the valuation model is tested as a single hypothesis. The results of the tests show that the variance bound is not violated; hence, the validity of valuation model cannot be rejected.

In ongoing research, we apply West's [13] speculative bubble test to a price series obtained from Brock's asset pricing model in an attempt to examine the power of the test. We suspect that, West [13] type bubble tests might also falsely signal for bubbles when carried out with price series generated from a production based asset pricing model with heterogeneous firms which by construction produces the maximally possible amount of welfare for society.

\section{References}

[1] R.J. Shiller, Do stock prices move too much to be justified by subsequent changes in dividends?, Am. Econ. Rev. 71 (1981) $421-436$.

[2] A.W. Kleidon, Variance bounds tests and stock price valuation models., J. Polit. Econ. 94 (1986) 953-1001.

[3] C.R. Nelson, C.I. Plosser, Trends and random walks in macroeconomic time series: some evidence and implications, J. Monet. Econ. 10 (1982) 139-162.

[4] S.F. LeRoy, R.D. Porter, The present-value relation: tests based on implied variance bounds, Econometrica 49 (1981) $555-574$.

[5] K.D. West, Bubbles, fads and stock price volatility tests: a partial evaluation, J. Fin. 43 (1988) 639-655.

[6] R.W. Michener, Variance bounds in a simple model of asset pricing, J. Polit. Econ. 90 (1982) 166-175.

[7] J.H. Stock, Tests of market efficiency when consumers are risk averse, reproduced, University of California-Berkeley, 1982.

[8] S.F. LeRoy, Efficiency and the variability of asset prices, Am. Econ. Rev. 74 (1984) 183-187.

[9] M. Flavin, Excess volatility in the financial markets: a reassessment of the empirical evidence, J. Polit. Econ. 91 (1983) $929-956$.

[10] G.N. Mankiw, D. Romer, M.D. Shapiro, An unbiased reexamination of stock market volatility, J. Fin. 40 (1985) 677-687.

[11] T.A. Marsh, R.C. Merton, Dividend variability and variance bounds tests for the rationality of stock market prices, Am. Econ. Rev. 76 (1986) 483-498.

[12] W.F.M. DeBondt, R. Thaler, Does the stock market overreact?, J. Fin. 40 (1985) 793-805.

[13] K.D. West, A specification test for speculative bubbles, Q. J. Econ. 102 (1987) 553-580.

[14] J. Tirole, On the possibility of speculation under rational expectations, Econometrica 50 (1982) 1163-1181.

[15] R.S. Gurkaynak, Econometric tests of asset price bubbles: taking stock. FEDS working paper, (2005), Board of Governors of the Federal Reserve System.

[16] A.W. Kleidon, Bias in small sample tests of stock price rationality, J. Bus. 59 (1986) $237-261$.

[17] R.J. Shiller, Stock prices and social dynamics, Brookings Pap. Econ. Act. (1984) 457-498.

[18] J.Y. Campbell, A.S. Kyle, Smart money, noise trading and stock price behavior, Rev. Econ. Stud. 60 (1993) 1-34.

[19] J.B. DeLong, A. Schliefer, L.H. Summers, R.J. Waldmann, The economic consequences of noise traders, J. Polit. Econ. 98 (1990) $703-738$ 
[20] J.Y. Campbell, R.J. Shiller, Stock prices, earnings, and expected dividends, J. Fin. 43 (1988) 661-676.

[21] J.Y. Campbell, R.J. Shiller, The dividend-price ratio and expectations of future dividends and discount factors, Rev. Fin. Stud. 1 (1989) 195-228.

[22] R. Rodriguez, F. Restoy, I.J. Pena, Can output explain the predictability and volatility of stock returns?, J. Int. Money Fin. 21 (2002) $163-182$.

[23] R. Bansal, C. Lundblad, Market efficiency, asset returns, and the size of the risk premium in global equity markets, J. Econometr. 109 (2002) 195-237.

[24] R. Bansal, A. Yaron, Risks for the long-run: a potential resolution of asset pricing puzzles, J. Fin. 59 (2004) $1481-1509$.

[25] G. Bekaert, E. Engstrom, Y. Xing, Risk, uncertainity, and asset prices, FEDS Working Paper No. 40, Board of Governors of the Federal Reserve System, 2005.

[26] M. Lettau, S. Ludvigson, J. Wachter, The declining equity premium: what role does macroeconomic risk play? NBER Working Paper No. 10270, 2004.

[27] M. Pritsker, Large investors: implications for equilibrium assets returns, shock absorption, and liquidity, FEDS Working Paper No. 36, Board of Governors of the Federal Reserve System, 2006.

[28] W.A. Brock, An Integration of Stochastic Growth and the Theory of Finance-Part 1: The Growth Model, Academic Press, New York, pp. 165-192.

[29] M.H. Miller, F. Modigliani, Dividend policy, growth, and the valuation of shares, J. Bus. 34 (1961) $411-433$.

[30] K.L. Judd, Computational economics and economic theory: substitutes or complements?, J. Econ. Dynam. Control 21 (1997) 907-942.

[31] W.A. Brock, Asset prices in a production economy, in: J.J. McCall (Ed.), The Economics of Information and Uncertainty, University of Chicago Press (for N.B.E.R.), Chicago, 1982.

[32] L. Akdeniz, W.D. Dechert, Do CAPM results hold in a dynamic economy. A numerical analysis, J. Econ. Dynam. Control 21 (1997) 981-1003.

[33] R.E. Lucas, Asset prices in an exchange economy, Econometrica 46 (1978) 1429-1445.

[34] K.L. Judd, Projection methods for solving aggregate growth models, J. Econ. Theory 58 (1992) 410-452.

[35] J.Y. Campbell, J.H. Cochrane, By force of habit: a consumption-based explanation of aggregate stock market behavior, J. Polit. Econ. 107 (1999) 205-251. 